\title{
Promoting appreciation of the study and practice of medicine: inner workings of a Mini-Med program
}

This article was published in the following Dove Press journal:

Advances in Medical Education and Practice

16 June 2012

Number of times this article has been viewed

\author{
Jacob Jay Lindenthal' \\ Joel A DeLisa ${ }^{2}$ \\ 'Department of Psychiatry, Institute \\ for the Public Understanding of \\ Health and Medicine, ${ }^{2}$ Department of \\ Physical Medicine and Rehabilitation, \\ University of Medicine and Dentistry \\ of New Jersey, New Jersey Medical \\ School, Newark, NJ, USA
}

\begin{abstract}
Dissatisfaction with the restrictions of the health care system, diminished reliance on the word of health care professionals, increased costs of medical care, and access to information online have increased consumers' interest in their own health care as well as their thirst for medical literacy. Mini-Med programs run by medical schools offer a more reliable method of learning about disease and disorders than does the indiscriminate surfing of the Internet. This article describes the efforts of the University of Medicine and Dentistry of New Jersey - the largest public university of the health sciences in the nation - to run and maintain such a program. The Mini-Med course provides lay students with insight into what a student undergoes while studying medicine and guides them through complex topics that range from anatomy and basic life support to the latest in stem cell research. It also provides early guidance for potential medical students, addresses patients' concerns, and gives some insight into the levels of comprehension of current medical students.
\end{abstract}

Keywords: Mini-Med program, medical education, consumer education, health literacy

Consumers today are increasingly more involved in their own health care; they are relying less on the word of medical authority figures and asking more questions about their health care options. The motivation for this shift was created in part by dissatisfaction with the restrictions of managed care, the increased costs of medical care, and the increased availability of information.

However, consumerism in health care is not new. More than two centuries ago, England and Wales witnessed the spread of medical care clubs and friendly societies that contracted with physicians to provide health care to low-income workers. By 1874, 8 million individuals were involved in physician-patient relationships; this ultimately led to the British National Health Service and to capitation (ie, so much per member per year) as a method of payment (as compared with fee for service). ${ }^{1}$

Today, patients are being asked to assume greater responsibility for their own health care, to spend their health benefits more wisely, and to be aware of the costs associated with their unhealthful behaviors. Assisting consumers with this task of partnering in their own health care are online networks, databases, and a myriad of Web sites. The explosion of electronic media and a vastly increased commitment to the building of consumer-oriented organizations are expected to lower costs while increasing access to health care information. ${ }^{2}$

\section{Focus on consumer education}

Unlike indiscriminate Internet surfing - which can be misleading at best and harmful to a person's judgment or health at worst - consumer education promotes the 
transparency of information and empowers patients to make decisions related to quality, cost, access, and innovation. Employers, too, recognize the importance of consumer education before making product-purchasing decisions. According to a nationwide survey of American employers, half expected to introduce or expand a wellness program in 2010, and a third planned to introduce or expand financial incentives designed to enhance health and thereby lower the health care costs of their employees. ${ }^{3}$ In addition, in 2004, the Institute of Medicine reported that improved health literacy can lead to a reduction of billions of dollars in avoidable health care costs. ${ }^{4}$ There is a growing consensus that health literacy "is the single largest, albeit least understood barrier to improving health care in the United States today," and it has tremendous implications for employers and employee productivity. ${ }^{5}$ The need to devote increased attention to consumer education was highlighted by data from the Centers for Disease Control and Prevention, which suggested that only $10 \%$ of the health of Americans is attributable to the health care system, whereas $50 \%$ is directly attributable to individuals' behaviors and lifestyles. ${ }^{6}$

An online national survey was conducted by the Deloitte Center for Health Solutions in October 2008; it included a representative sample of 4001 Americans plus 1664 people 18 years old and older who were randomly selected and surveyed for the purposes of adequate subsampling. ${ }^{7}$ More than half of respondents (54\%) reported attempting to learn more about their personal health risks, and 57\% sought information online during the previous year about treatment options or a specific treatment; $68 \%$ of consumers with chronic conditions sought information about their conditions. Fewer than half of these individuals were actively pursuing healthful behaviors such as eating well, managing their weight, or participating in a wellness or healthy living program. ${ }^{7}$

\section{Health literacy}

Health literacy has been defined as "[t]he degree to which individuals have the capacity to obtain, process, and understand basic health information and services needed to make appropriate health decisions." 8 It requires understanding the instructions on prescriptions, appointment slips, medical education brochures, doctor's directions, hospital release forms, and consent forms. Today, it also requires knowing how to navigate complex health care systems. Limited literacy correlates with poor glycemic control in patients with diabetes, with the improper use of metered-dose inhalers in patients with asthma, and with the poor control of hypertension in patients with hypertension. ${ }^{9-11}$ According to the National
Academy on an Aging Society, low literacy resulted in an additional $\$ 73$ billion in 1998 being spent for health care costs. Although it was responsible for fewer doctor visits, low health literacy resulted in substantially more hospital resources, including 6\% more hospital visits and hospital stays that were 2 days longer. ${ }^{12}$

\section{Mini-Med schools}

Although consumer education has emerged as a key to enhancing health and reducing cost, little attention is usually paid in medical schools to the training of physicians as they are increasingly called upon to educate their patients as well as the public at large. Mini-Med schools have been developed throughout the United States and elsewhere in response to the need for consumer education as well as to enhance physician education. Among the strengths of these programs are that they enroll consumers who range from the sickest to the healthiest and that they encourage the participation of those who are already involved in decision making as well as those who are not. They also afford future physicians the opportunity to interact with a variety of patient types, and they help these individuals to understand conditions, treatments, and the mechanisms of action of certain drugs. They also allow medical students to hear firsthand how a medical condition or drug is perceived, to see how a condition affects a patient and that patient's family members, and to witness patients' frustration and fear as they relate to the doctor's office.

Mini-Med schools are the brainchild of J John Cohen, $\mathrm{MD}, \mathrm{PhD}$, who is a professor of immunology and medicine at the University of Colorado Denver School of Medicine. The schools were designed to assist the lay public with gaining an understanding and appreciation of the practice of medicine and the delivery of health care. These schools are presently located in at least 34 states and 3 countries, and they vary significantly with regard to structure, governance, and course content. All include a series of lectures and demonstrations that are provided to the public at a nominal cost and that are conducted when facilities are not in use for students who are enrolled in accredited courses. Mini-Med schools are generally sponsored by medical schools and organized by the Office of Science Education of the National Institutes of Health under the direction of Dr Victor Fuchs. The National Institutes of Health maintains websites that describe MiniMed schools and how to plan them, and it provides the locations of currently active schools.

The following is a report of one such program that has been in operation for more than a decade. This program was designed to address the needs of diverse populations of 
consumers and to help medical students become effective medical educators.

\section{The University of Medicine and Dentistry of New Jersey/New Jersey Medical School Mini-Med school and Pre-Medical Honors program}

The University of Medicine and Dentistry of New Jersey (UMDNJ) is the largest public university of the health sciences in the United States. The university was created to unify all of New Jersey's public medical and dental education programs. Founded in 1970 by an act of the State Legislature as the College of Medicine and Dentistry of New Jersey, the New Jersey Medical School (NJMS) is the oldest state medical school in New Jersey. It is located in Newark, NJ, which is a city with a population of 278,154 . The major ethnic groups of the city include blacks (47.8\%), Hispanics (32.3\%), and whites (16.3\%). Approximately $58 \%$ of persons who are 25 years old and older are high school graduates; $9 \%$ hold bachelor's degrees, and another 3\% have earned graduate or professional degrees. ${ }^{13}$ The Mini-Med school program at UMDNJ was modeled on the National Institutes of Health recommendations $;{ }^{14}$ however, this program was designed specifically to meet the needs of the larger Newark community. This Mini-Med school program is sponsored by the Office of the Dean and the Hispanic Center for Excellence, and the Healthcare Foundation of New Jersey, Pfizer, and private contributions have provided support for the program over the years. The objective was to keep the program affordable for a broad spectrum of the lay public.

\section{Mission statement and program goals \\ Mini-Med school}

The UMDNJ/NJMS Mini-Med school was designed to educate the public, which is made up of individuals who are becoming increasingly dissatisfied with the misinformation and conflicting reports that surround health and medicine.

A significant contributor to the loss of confidence in medical information and to unhappiness among the lay public derives from a misunderstanding of the role of health care providers regarding "[w]hat they can and cannot do, why they do it, and how they do it." Thus, the Mini-Med school at the NJMS has adopted the philosophy that an educated patient is the doctor's best ally.

Approximately 250 students are admitted to each session of the program, and $90 \%$ of these students graduate.
Students must attend at least 6 of the scheduled 8 sessions to graduate from the program. Those who fail to meet this standard may make up their deficiencies by enrolling in a succeeding program. Out of respect to prospective medical students, lectures are delivered at a high academic level. Students consistently rise to the intellectual challenge posed by the high standards that have been set, and they have applauded this aspect of the program. Indeed, professors are often challenged by the questions that the lay students pose.

The Curriculum Committee formed by the dean of the NJMS is charged with advising and overseeing the Mini-Med program. Decision making that involves curriculum design and content, scheduling, tuition fees, and financing is completed 10 months in advance of the start of each program to provide ample time for course preparation. The Curriculum Committee also meets while the program is in session to evaluate the effectiveness of the curriculum design and its implementation.

\section{Pre-Medical Honors program}

The Pre-Medical Honors program admits third-year high school students on a first-come, first-served basis with the written approbation of their teachers or guidance counselors. This program consists of a high concentration of inner city youth from Newark and Jersey City, NJ, which are the two largest metropolitan areas in the state. Students must have successfully completed a yearlong course in the basic sciences. The goal of the Pre-Medical Honors program has been to provide 250 high school students with an introduction to the following: (1) the elements of basic science and clinical medicine; (2) the practices that are necessary to prevent disease and promote health; (3) the requirements for becoming a physician; (4) the bioethical challenges of the delivery of modern health care; and (5) the career opportunities within the field of medicine. Eight sessions are offered once a week in the evenings to accommodate the working men and women who teach the sessions as well as the students' school schedules.

\section{Select appropriate faculty}

The NJMS faculty and their colleagues at affiliated schools of dentistry and allied health and at the University Hospital in Newark are the principal sources for lecturers in the Mini-Med school program. In addition to being thoroughly conversant in their disciplines, those chosen to participate must possess the ability to discuss their expertise at a level that is comprehensible by the general public. Another challenge involves 
choosing relevant topics, suitable language, and appropriate media that will capture the imagination of both the public and the lecturer.

\section{Link healthy students with medical educators}

The objective of the Mini-Med school is to establish a direct linkage with the ultimate beneficiaries of health care: the consumers. Consumers become particularly attuned to health care most often when they are ill and infirm. Therefore, it is important to introduce the public to the field of medicine when they are ostensibly healthy and in a better position to assimilate important issues that are relevant to their well-being.

One of the roles of the physician is that of educator. Introducing physicians-in-training to a nonpatient public has the potential to heighten their effectiveness as physicians. The NJMS Mini-Med program offers medical students the opportunity to learn how to educate patients while they are becoming sensitized to patients' concerns. Involving their own medical students as educators is consistent with the NJMS Committee on Academic Programs and Policies statement that was adopted on February 16, 1999: “... studentinitiated community service learning programs are an integral component of the value system of the New Jersey Medical School and should be incorporated in the academic programs of the school."

\section{Preceptorship}

Forty-five first- and second-year medical students participate in the Mini-Med school program as preceptors. First-year medical student preceptors are chosen by their second-year peers who participated in the previous year's Mini-Med school program. Interested medical students are asked to write a brief essay relating why they want to participate in the program and to describe what qualifies them for preceptorship. Preceptor directors (ie, a core group of organizers) are responsible for collecting fees from, overseeing the activities of, and maintaining the attendance records of their fellow student colleagues and program participants. Faculty lecturers are advised that they might be asked to present their material in abbreviated form to the medical students before the program begins. Upon request, all student preceptors must assist lecturers with the preparation of both live and online presentations. These student preceptors are also required to familiarize themselves with reading material suggested by the lecturers, and they must be prepared to answer questions from Mini-Med school program participants.

\section{Micro-Med course}

The Micro-Med course is part of the Mini-Med program. It covers the rudiments of health care and disease by looking at topics such as epidemiology, biostatistics, pharmacology, hypertension, heart disease, cancer, diabetes, human immunodeficiency virus/acquired immunodeficiency syndrome, methicillin-resistant Staphylococcus aureus, influenza, sexually transmitted diseases, and the doctor-patient interview. Preceptors discharge their administrative responsibilities for a 75-minute seminar during which they are encouraged to deliver impromptu lectures on topics that they may be studying and to cover the material discussed in the Micro-Med course.

Medical students who take part in the Mini-Med school and Pre-Medical Honors programs for 4 semesters receive elective credit in the form of 2 weeks of free time to interview for residencies during their senior years.

\section{Access and outreach}

Students can access archived lectures by consulting the UMDNJ's website for the Mini-Med school program (http://www.umdnj. edu/minimed) and then proceeding to iTunes. Participants are provided with an e-mail address (minimedschool@gmail.com) to use to communicate their concerns to members of the faculty, medical student preceptors, and program administrators. News and noteworthy items are communicated back to the students via e-mail, and announcements delivered at the end of each session are also sent with the use of this e-mail account.

The program offers outreach sessions to provide health education to individuals who are unable to travel to the NJMS campus, including incarcerated men and women, wayward adolescents, homeless persons, and abused women. Classes for homeless people, prisoners, and abused women take place in prisons and shelters. Arrangements that involve course content and scheduling are made a year in advance with prison and shelter administrators. Attendance records for these sessions are the responsibility of the administrators of the participating institutions. Lectures and handout materials are created by medical students, and these are designed to meet the specific needs of the participating groups.

\section{Mini-Med course content}

Course content is based largely on student demand, and an effort is made to balance both the basic and the clinical sciences.

\section{Nonelective course}

\section{Stem cell research}

To help ensure that students are provided with the latest information, members of the NJMS Stem Cell Society, 
which include faculty members and graduate students, have been integrated into the program. A 1-hour introduction to stem cells is followed by other lectures that are delivered on an ad hoc basis to deal with the potentials and limitations of cell research as they relate to specific topics in the curriculum.

\section{Elective courses}

\section{Basic life support}

Interested students can become certified in basic life support. This program is administered by the Community Training Center of University Hospital in Newark, and it is scheduled on the weekends.

\section{Medical librarianship}

The effective promotion of health and prevention of disease necessitates individuals knowing how to navigate the Internet as well as how to determine the value of medical information that is presented there. Consistent with the program philosophy, which stresses lifelong learning, the Mini-Med school is committed to the promotion of selfeducation. Senior research librarians conduct tutorials at UMDNJ's George F. Smith Library. These tutorials include a review of the major textbooks, websites, and databases that are employed in medical school curricula; advice about the evaluation of medical literature; and a review of search functions. Students are provided with handouts for future reference.

\section{Cardiopulmonary physiology}

A 90-minute cardiopulmonary physiology lecture is offered. This is followed by a live demonstration of the electrocardiogram, how to interpret it, and its benefits.

\section{Pathology: lecture, demonstration, and tour}

Students can avail themselves of a 75-minute presentation that involves autopsy specimens. This experience offered by senior faculty in the Department of Pathology and Laboratory Sciences. After a 45-minute lecture, interested students are gowned and invited to handle the specimens.

\section{Hospital tours}

Tours of selected areas of University Hospital are offered, including facilities that provide radiology and respiratory therapy; the special care nursery; the physical therapy area; the laboratory; and the emergency department triage system, which involves psychiatric, trauma, pediatric, acute care, and fast-track facilities.

\section{Screening clinics}

The Department of Marketing and Media Relations sponsors screening clinics. Under the direction of faculty drawn from the Department of Medicine, medical students are given the opportunity to screen program participants. Mini-Med students are screened for a variety of diseases, including hypertension, glaucoma, diabetes, and hypercholesterolemia. Participants are advised about their health status, and reports are made available to their personal physicians. Those without physicians are invited to enroll in the university's own system. Several treatable diseases and conditions have been identified through our Mini-Med screening clinics.

\section{Program evaluation}

At the end of each session, participants are asked to evaluate the program. Information is sought about the following: (1) where students first learned about the program; (2) the appropriateness of lecture topics; (3) the quality of the lectures; (4) the general ambiance of the program; and (5) the food quality and service. Participants are also encouraged to provide their overall impressions and to make suggestions for future programs. Respondents consistently rate the performance of medical students, medical screening clinics, electives in librarianship, and basic life support as very high. Informal discussions with participants, faculty, and medical students to learn about ways to make improvements to the program provide another source of participant satisfaction.

\section{Graduation requirements}

Graduation is contingent upon participants attending $80 \%$ of the sessions. Participants can graduate with honors by achieving a score of at least $80 \%$ on an online examination that has been composed by medical student preceptors. A graduation ceremony is held on the last night of the program, during which public medical education awards are presented upon the approbation of the dean and awarded to individuals thought to have made significant contributions to the program.

\section{Outcomes}

Sustained efforts over more than 12 years have yielded unanticipated rewards. Lay students in the Mini-Med school have in large part reported an increased appreciation of the rigors of medical studies and of the challenges that a physician faces when trying to educate patients about their conditions. The basic information about anatomy, including the examination of cadavers, often served to widen participants' frequently limited knowledge of their own bodies. 
Lay students appreciated the organization of the curriculum and often applauded the depth of information provided in each topic area. In many cases, they were motivated to take the course because of illnesses in their immediate families, and they were eager to learn more about particular diseases or disorders.

The Mini-Med course provides an introduction to dealing with and educating future patients for students who are seeking a medical career. In addition to first-hand experience with "patients," the course confers a degree of understanding of the plight of sick patients and the frustrations associated with not understanding complex topics or instructions. Lay students, who have now learned more about what a doctor undergoes while studying medicine, also learn where to go and where not to go for more information; in addition, they are better equipped to ask questions about their own health conditions or those of their loved ones.

Many young, capable students with long-standing career plans in areas other than health care have been motivated by the course to change their plans and enter various health and medical fields. Of at least equal importance are the many young students who have come to understand that their talents lie elsewhere. Having former medical students eventually join the Mini-Med school faculty is its own reward.

\section{Disclosure}

The authors report no conflicts of interest in this work.

\section{References}

1. Wolfe S. Consumerism and health care. Pub Admin Rev. 1971;31(5): 529-536. Available from: http://www.jstor.org/pss/974974. Accessed April 19, 2012.
2. Turner G-M. Consumerism in health care: early evidence is positive. Health Issues [serial on the Internet]. August 11, 2005. http://www. galen.org/assets/Consumerism.pdf. Accessed April 19, 2012.

3. Blank K. Healthcare consumerism - lowering the cost curve. SelfFunding Magazine [serial on the Internet]. April 6, 2010. http://www. selffundingmagazine.com/article/consumerism-lowering-the.html. Accessed April 10, 2012.

4. Institute of Medicine. Health literacy: a prescription to end confusion. April 8, 2004. http://www.iom.edu/Reports/2004/Health-Literacy-APrescription-to-End-Confusion.aspx. Accessed April 19, 2012.

5. Cave D. Health literacy missing link in healthcare consumerism. http:// www.nurturhealth.com/pdf/articles-whitepapers/article-health-literacy. php. Accessed April 19, 2012.

6. Wye River Group on Healthcare. An Employers' Guide to Healthcare Consumerism. http://www.wrgh.org/docs/hc_consumerism_guide.pdf. Accessed April 19, 2012.

7. Deloitte. 2009 Survey of Health Care Consumers. A comprehensive assessment of consumer attitudes, behaviors and unmet needs. http:// www.deloitte.com/US/2009consumersurvey. Accessed April 19, 2012.

8. US Department of Health and Human Services. Healthy People 2010. http://www.healthypeople.gov/Document/pdf/uih/2010uih.pdf. Accessed April 12, 2011.

9. Schillinger D, Grumbach K, Piette J, et al. Association of health literacy with diabetes outcomes. JAMA. 2002;288(4):475-482.

10. Williams MV, Baker DW, Honig EG, Lee TM, Nowlan A. Inadequate literacy is a barrier to asthma knowledge and self-care. Chest. 1998;114(4): 1008-1015.

11. Williams MV, Baker DW, Parker RM, Nurss JR. Relationship of functional health literacy to patients' knowledge of their chronic disease. A study of patients with hypertension and diabetes. Arch Intern Med. 1998;158(2):166-172.

12. Georgetown University, Center on an Aging Society. Health literacy fact sheet. http://hpi.georgetown.edu/agingsociety/pubhtml/healthlit. html. Accessed April 19, 2012.

13. City-Data.com. Newark, New Jersey. http://www.city-data.com/city/ Newark-New-Jersey.html. Accessed April 2, 2011.

14. National Institutes of Health. Mini-Med school planning guide. http:// science-education.nih.gov/home2.nsf/DC+Area+Programs/+MiniMed+School/CD8E49A582CE63E485256FFC006B2461. Accessed April 19, 2012.
Advances in Medical Education and Practice

\section{Publish your work in this journal}

Advances in Medical Education and Practice is an international, peerreviewed, open access journal that aims to present and publish research on Medical Education covering medical, dental, nursing and allied healthcare professional education. The journal covers undergraduate education, postgraduate training and continuing medical education

\section{Dovepress}

including emerging trends and innovative models linking education, research, and healthcare services. The manuscript management system is completely online and includes a very quick and fair peer-review system. Visit http://www.dovepress.com/testimonials.php to read real quotes from published authors. 